\title{
IMAGENS EM MOVIMENTO, TEMPORALIDADES E O EFEITO CINEMA NOS MUSEUS DE ARTE
}

\author{
Patricia Ferreira Moreno* \\ Universidade Federal de Juiz de Fora
}

\section{RESUMO}

Os artistas modernos e contemporâneos que lançaram mão da imagem em movimento como suporte inseriram de forma diferencia$\mathrm{da}$ as discussões sobre as questões temporais no fazer artístico. A partir de então, novas formas expositivas vêm sendo buscadas pelos museus e galerias que se propõem a abrigar obras relacionadas aos suportes da imagem em movimento. Dessa forma, pretendemos discutir como a produção artística e o espaço expositivo realizam $\circ$ processo de musealização de temporalidades e constroem o que chamamos aqui de um cinema - museu.

\section{PALAVRAS-CHAVE}

filme de artista; temporalidades; cinema; Arte Contemporânea, museus.

\begin{abstract}
The modern and contemporary artists who have used the moving image as a support inserted differently discussions about temporal matters in art making. Since then, new exhibition forms are being sought by museums and galleries that expose works related to moving image media. we intend to discuss how artistic production and exhibition space musealization perform the process of temporalities and build what we call here a cinema - museum.
\end{abstract}

\section{KEY-WORDS}

Artist film; temporalities; cinema; Contemporary art; museums.

"Professora do Instituto de Artes e Design da Universidade Federal de Juiz de Fora - IAD-UFJF, atuando na área de História da Arte Moderna e Contemporânea. 
O que é o tempo? Um segredo - insubstancial e impotente.

Um pré-requisito do mundo externo, um movimento

desordenado e diluído em corpos que existem e se movem no espaço. Mas o tempo existiria se não houvesse o movimento? Haveria o movimento se o tempo não existisse?

Que questão! O tempo é uma função no espaço? Ou vice-versa? Ou os dois são coidênticos? Uma questão ainda maior!

(Thomas Mann - A montanha mágica. p. 339)

Thomas Mann no trecho acima nos desafia a pensar sobre a relação tempo-espaço-movimento em uma perspectiva que ultrapassa as discussões da física. “O tempo existiria se não houvesse o movimento?", no objeto de estudo que aqui propomos a resposta pode ser emitida de imediato: não! Essa certeza é possível porque a discussão tempo/movimento se fez presente nas propostas pensadas pelos artistas modernos e foi desdobrada na Arte Contemporânea em suas construções processuais e suas temporalidades. Tais noções levaram os artistas a produzirem obras que discutem sobre as relações espaço-tempo, buscando possibilitar, dentre outras questões, a apreensão do processo artístico em "tempo real".

Reconhecer o ímpeto para as discussões sobre as temporalidades por parte dos artistas e, principalmente, a busca pela elaboração em "tempo real" é importante para respondermos às questões centrais das reflexões que aqui propomos: primeiramente, de que forma e em quais âmbitos a linguagem cinematográfica, por sua potencialidade em "captar o real" e trabalhar, simultaneamente, com temporalidades multifacetadas, influenciou a produção artística do século $X X$ ? Posteriormente, como uma parte dessa produção artística lançou mão do chamado "efeito cinema"| e como o espaço expositivo tornou-se o principal elemento nesse processo?

Nicolas Bourriaud (20II), no livro "Formas de Vida: a arte moderna e a invenção de si”, introduz uma ideia convergente à nossa reflexão. Para ele o cinema apresentou aos artistas a possibilidade de representar o real para além de qualquer mediação linguística.Assim, a influência do cinema na Arte Moderna incide muito mais sobre os meios da Arte do que sobre o modo de representação. Dessa forma, o cinema teria viabilizado a expressão da realidade por meio da própria realidade, pois "preso ao real para todo sempre, sua essência reside no presente" (Bourriaud, 20II: 35).

Para Bourriaud a primeira obra de arte a tirar consequências do cinema foi Roda de Bicicleta, seguido pelos outros ready-mades de Marcel Duchamp. Segundo ele, Duchamp teria utilizado a possibilidade cinematográfica de significar através da própria realidade, dispensando, assim, o intermédio da representação e, seguindo o mesmo raciocínio, o museu passa a cumprir o papel da película, pois, nos ready-mades, a instituição artística constitui um modo de registro. Dessa forma, o ready made não só assinala a irrupção do objeto comum e de consumo no campo museal, mas também indica a passagem de um espaço simbólico para um tempo real do objeto, indexado sobre o modelo cinematográfico, porque "criar é enquadrar: o tempo vivido e o tempo da criação se sobrepõem um ao outro" (idem: 37 ).

\footnotetext{
I $O$ termo, como veremos adiante, foi criado por Philippe Dubois e aqui nos apropriamos dessa ideia e a estendemos, propondo uma compreensão de alcance mais alargado, pois a utilizamos para perceber a influência da linguagem cinematográfica nas artes plásticas, principalmente sua presença nos espaços expositivos, a partir da Arte Moderna, tendo como marco inicial os ready mades de Duchamp.
} 
O modus operandi do cineasta pode ter influenciado a operação artística ao fornecer um modelo de prática do presente capaz de transformar seus métodos de produção e exposição. Não por acaso as manifestações pós ready mades e filiadas ao pensamento Duchampiano fazem menção a uma necessidade de expressão "direta", articulando conjunta e intrinsecamente os conceitos de obra, processo e tempo presente.

Philippe Dubois também analisou tais confluências e propôs o termo "efeito cinema" para designar a prática que associa obra/espaço expositivo/ espectador à linguagem cinematográfica.

(...) o espaço expositivo (ou, ao menos, o da instalação) é transformado em uma espécie de equivalente espacial do filme na trajetória do espectador (...) a exposição se desenrola no espaço como um filme que o espectador segue passo-a-passo (...) visitar a exposição se torna ver um filme e mostrar equivale a montar (2009: 209).

Os filmes e vídeos de artista são objetos privilegiados para a compreensão desse processo. Os filmes de artista e suas derivações como a vídeoarte e a videoinstalação são categorias artísticas consolidadas e, atualmente, ganharam uma atenção privilegiada por parte dos espaços expositivos, que buscam pensar em meios e em configurações diferenciadas para exibi-las.

Trabalhos pioneiros já demonstram a potencialidade da utilização do cinema como expressão pelos artistas de vanguarda, a apreensão do que entendiam como "tempo real" permeou a grande maioria deles. Duchamp, por exemplo, lançou mão do recurso cinematográfico como "atalho" para conseguir materializar seus efeitos óticos como em Anémic cinema, de 1926, filme constituído por sucessivas imagens espiraladas, uma tentativa de fazer o registro do movimento pretendido em obras anteriores, como Rotative d'émisphere, de 1925. Muitos outros artistas de vanguarda realizaram experimentações com o suporte cinematográfico, para mencionarmos apenas alguns, a título de referência: futuristas publicaram em 1916 o primeiro manifesto do cinema de artista, intitulado Manifesto da cinematografia futurista. Os dadaístas Hans Richter e Viking Eggeling, no início da década de 1920, criaram filmes compostos por abstrações, pois entendiam o cinema como um prolongamento natural da pintura. Cabe mencionar também o estreitamento das relações entre arte e cinema, como podemos perceber nos trabalhos de Man Ray, Léger, Moholy-Nagy, Salvador Dali (em parceria com Luis Buñuel, no conhecido Um Cão Andaluz), Picabia e muitos outros dessa época. É possível afirmar, então, que, a partir daí a modalidade filme de artista tornou-se parte da agenda de várias produções em diversos momentos e apresentando diferenciadas modalidades. (Cocchiarale; Parente, 2007; Canongia, 198I).

Nos anos 1960, Andy Warhol transgrediu a narrativa convencional em seus filmes experimentais, ao filmar continuamente os rostos de personagens entrevistados por ele ou apresentar como narrativa um período de quase seis horas ininterruptas de sono de um jovem no filme sleep. A importância da produção fílmica de Warhol deve ser pensada como divisor de águas no que tange ao uso do suporte fílmico por artistas, Chelsea Girls, de Andy Warhol e Paul Morrissey (1966), por exemplo, tornou-se uma referência para o cinema experimental da década de 1960. Em Chelsea Girl Warhol rompeu com todas as regras de montagem/projeção/exibição do cinema convencional ao utilizar a projeção em duas telas simultâneas - uma em preto e branco e a outra em cores - e duas trilhas sonoras diferentes, mas associadas. Em cada exibição há um resultado diferente, pois não há uma obrigatoriedade cronometrada entre as duas projeções. Além disso, as imagens em movimento captadas por Warhol, 
quando exibidas, muitas vezes eram projetadas diretamente sobre uma tela de pintura, o que nos dá uma importante pista para compreendermos as relações intrínsecas que passaram a se estabelecer entre a arte e o cinema. $O$ uso da imagem em movimento criava novas possibilidades para uma arte que pretendia ampliar os limites da tela com imagem fixa ou da escultura estática e serviria como um novo espaço visual e um novo suporte de experimentação. Mais ainda: os artistas pretendiam reaproximar a produção artística do cotidiano e das experiências comuns.

De um lado temos as concepções artísticas que promoveram questionamentos à linguagem cinematográfica tradicional, de outro temos exposições que lançam mão da narrativa cinematográfica como fio condutor. Nesse sentido, interessa-nos refletir como as obras de alguns artistas, que usam a imagem em movimento em seu repertório, vêm sendo expostas atualmente, a fim de compreendermos como os espaços expositivos reelaboram o discurso, transportando-o para as discussões atuais, permeadas pelas demandas do nosso tempo.

Museus e galerias, imbuídos de um formato que vem se tornando usual nas exposições de Arte Contemporânea, constroem espaços que buscam desvelar o conteúdo das obras em um ambiente entendido como propicio à fruição, mas que, cabe mencionar aqui, em alguns casos, podem se organizar de maneira conceitualmente contraditória aos princípios de ruptura que fomentaram as propostas dos artistas que utilizaram a imagem em movimento como suporte.

É, por exemplo, uma tendência atual nas exposições o abandono do uso de um monitor em prol da imagem projetada diretamente no espaço expositivo, gerando, em muitos casos, uma multiplicidade de projeções e variados ambientes imagéticos, o que permite maior contágio na organização da linguagem do filme, slide ou vídeo com novos subsídios simbólicos. Um exemplo desse tipo de construção expositiva se encontra na Galeria Cosmococa ${ }^{2}$, no Instituto de Arte Contemporânea Inhotim, bem como na Galeria Miguel Rio Branco construída na mesma instituição.

Tais recursos expositivos nos levam a uma discussão que atravessa as fronteiras fragilmente delineadas entre a Arte Moderna e a Arte Contemporânea: a menção às temporalidades. Kátia Maciel (2009) menciona a existência, na atualidade, de uma situação-cinema que se constrói pela espacialização da projeção num ambiente específico em que o espectador é pensado como parte ativa do processo. A autora utiliza o termo transcinema para designar essa nova construção de espaço-tempo cinematográfico, em que a experiência das artes visuais e do cinema possibilita um espaço para o envolvimento sensorial do espectador.Talvez essa alteração na relação espectador/obra, que mencionamos anteriormente, tenha influenciado a postura atual do público, hoje muito mais receptivo às obras de interação entre imagem e ambiente. Percebemos, então, uma modificação significativa no que se refere a ideia de promover a operação artística in loco, uma das proposições dos artistas da década de 1970, pois esse formato faz alusão à múltiplas temporalidades simultaneamente, uma demanda própria do nosso tempo.

${ }^{2}$ Trata-se um espaço específico (site specific) no Instituto de Arte Contemporânea Inhotim, chamado de galeria Cosmococa para a fruição das obras que leva em consideração algumas das premissas pensadas pelos artistas, quando da sua concepção. Para conhecer as ideias de Oiticica e Neville acerca da montagem das cosmococas e a forma como o Inhotim realizou esse espaço expositivo, bem como suas limitações em relação às concepções dos artistas pode ser consultado o artigo: A Cosmococa de Oiticica: discussões sobre a relação obralespaço de fruição, apresentado por mim no XXXII Colóquio do Comitê de História da Arte em outubro de 2012 e disponível em http:// www.cbha.art.br/coloquios/2012/anais/pdfs/artigo_s4_patriciamoreno.pdf . 
No que se refere a essas múltiplas temporalidades, as instalações artísticas, principalmente as de videoarte, têm cada vez mais sugerido um "novo olhar e um novo dizer", pois o tempo se constitui como uma experiência subjetiva, o tempo do narrador difere do tempo do que é narrado, sendo esta "imagem" de tempo um artifício para darmos concretude à vida.

Por isso uma questão que vem se tornando um importante objeto de nossos estudos é a alteração na relação obra/musealização/espaços expositivos, tripé que, ao combater a tradicional passividade do olhar meramente observador, torna-se parte protagonista de um estágio adequando às demandas do público em um momento cujos limites da arte não poderiam mais ser construídos de forma exógena. Acreditamos que "Musealizando temporalidades" ampliou-se os repertórios artísticos e as modalidades das experimentações surgidas realizam, a cada exposição, uma nova experiência. Assim, verificamos que a musealização de obras que utilizam a imagem em movimento como suporte proporcionou a criação de um cinema-museu, com imbricações específicas, de caráter contraditório, heterodoxo e cheio de nuances, conforme veremos a seguir.

Nesse cinema-museu as noções de espaço e de temporalidade ao serem desdobradas tornaram-se múltiplas e multifacetadas. Surgem, então, experiências em que filmes não são mais vistos na sala escura do cinema tradicional, mas nas galerias, museus, exposições, instalações. A questão que se coloca é: o que se passa com esse gênero específico de projeção de imagens? Para amparar essa reflexão voltemos ao que Philippe Dubois denominou de "efeito Cinema na Arte Contemporânea”.A discussão levada a cabo por Philippe Dubois em sua concepção de pós-cinema, atesta que a experiência de cinema tal como conhecíamos antigamente foi modificada, havendo hoje novas experiências de cinema às quais ele chama de pós-cinema.

O que é interessante na utilização dessas imagens no cinema-museu é a ideia de que precisamos, tal como afirma Dubois, de uma experiência temporal, onde o tempo é dado como uma manipulação da percepção, por meio de objetos técnicos. Nossa percepção sobre a imagem não pode vir apenas construída através da técnica, mas da grande forma de pensamento que advém da técnica. Nessas experiências não se coloca o cinema e a fotografia como simples demonstração de uma realidade técnica, trata-se de discutir o princípio da imobilidade ou mobilidade diante do mundo, uma espécie de filosofia de tempo. É desse modo que o cinema ajuda a desenvolver um outro pensamento sobre o tempo, ou seja, o tempo da imagem como reprodutora do mundo, por sua dimensão temporal percebida em sua duração, ruptura e/ou continuidade.

O fato do cinema ser um "dispositivo" e de tratar-se de uma realidade técnica especifica com uma utilização social é fundamental para entender as transformações do cinema hoje, principalmente o caso do cinema de exposição, cuja inserção teve início na década de 1990. O chamado cinema de exposição se apropria da linguagem fílmica para ser exibido em galerias e museus é um tipo de "cinema" diferenciado e, por isso, colocado aqui entre aspas. Existem dois deslocamentos que caracterizam esse novo tipo de cinema:a) deslocamento do lugar (de cinema para museu), b) deslocamento de natureza estética (projeção convencional para exposição artística). Entre os dois há uma equação que só pode ser compreendida se o elemento tempo for levado em consideração, pois será a temporalidade, ou as temporalidades (no plural) que poderão dar conta de possibilitar essa compreensão dos deslocamentos, pois o filme de narrativa convencional, além de apropriado, teve seu tempo alterado para ser transmutado em obra de arte. Percebe-se também como a criação dos valores de exposição 
pela reprodutibilidade (diante da critica realizada por W. Benjamin) vai repercutir no cinema quando o valor da projeção é substituído por outra situação. Hoje em dia, podemos dizer que o cinema na sala de projeção tem um valor próprio (uma analogia de culto) e que a sala possui característica de espaço de culto, daí a crítica da reprodutibilidade da obra de arte de Benjamin.

Ainda com relação aos filmes que frequentam galerias e museus há alguns outros tópicos interessantes a serem notados. De acordo com Phillipe Dubois (2009) há quatro categorias a serem conhecidas: I) a de filme exposto; 2) a de filme decomposto/recomposto; 3) a própria reconstituição do filme; e 4) a construção do filme: o que se diferencia do filme projetado no cinema, pois este se desmaterializa conforme é projetado. Poderíamos na dimensão temporal do filme, materializar o que foi desmaterializado?

Exemplos significativos em que a temporalidade é fragmentada são dados pelo autor em palestra proferida na Universidade Federal de Santa Catarina, em meados de 2013. Na ocasião, Dubois elenca as obras de Douglas Gordon, tal como o 24 horas de Psicose, elaborada no início dos anos 1990. Nessa experiência o filme Psicose de Alfred Hitchcock é projetado em super câmera lenta por 24 horas. Nessa obra o que é privilegiado não é mais o tempo da narrativa, mas sim a construção temporal quadro a quadro, na qual é possível "experienciar" os ângulos, os cortes e o enquadramento em um outro sentido, permitindo a obtenção de imagens reveladoras sobre a construção fílmica de Hitchcock; outra experiência, realizada entre 1995 e 2000, trabalha o filme de John Ford, Rastro de ódio, nela o artista projeta o filme de pouco mais de duas horas, lenta e ininterruptamente durante 5 anos $^{3}$. Em ambos exemplos, a fragmentação e decomposição do filme, projetam uma outra realidade temporal fílmica diferente da sua concepção de origem. Tais filmes vêm sendo projetados em diversos museus do mundo, mas em fragmentos, de modo que só se tem acesso a partes do filme e não ele inteiro. Em ambas experiências podemos perceber a fragmentação ou dilatação do tempo do cinema quando apropriado por um artista e transmutado de seu lugar de origem para um espaço expositivo de arte.

Outras experiências de tempo e remontagem temporal em filmes que foram originalmente criados para serem exibidos em cinemas tradicionais e, tempos depois, foram apropriados em outras experiências tridimensionais são os chamados footages, ou filmes decompostos e recompostos, imagens de arquivos que são recompostos em outra narrativa. Grande ícone dessa linguagem desde os anos 1970 é a Escola Vienense, cujo maior nome é Martim Arnold, que reproduziu, por exemplo, por 25 min uma cena de 20 segundos.

No filme reconstituído, a ideia de remake é o foco. Há, portanto um novo tipo de deslocamento pois o remake sempre é falso, nunca é o original. Pierre Uig é um artista símbolo dessa modalidade de cinema na França. Para ele o remake é um retorno ao original, pois há uma ponte que une o original e a reconstituição. Em síntese todos esses apontamentos de Dubois, compilados de suas diversas entrevistas, aulas e escritos sinalizam para o fato de que o tempo no cinema é elemento chave não apenas nas narrativas possíveis, mas no delineamento das experimentações, independentemente dos espaços de projeção, suportes de filmagem ou propostas narrativas, estéticas ou políticas embutidas na projeção.

Assim, para buscar compreender sobre como o espaço expositivo tornou-se um lugar privilegiado para exibir a potencialidade do cinema com suas ${ }^{3}$ Disponível em: https://www.youtube.com/watch?v=bq8nYh6DWhA; Acesso em: 12 de novembro de 2015. 
temporalidades multifacetadas precisamos aprofundar um pouco mais a reflexão sobre o tempo, o elemento fundamental na composição e enredo desse museu cinema.

Estamos pensando aqui no tempo como a categoria essencial para o entendimento das narrativas cinematográficas. A noção de tempo é capital, tanto científica quanto existencialmente, e ao mesmo tempo, muito difícil de definir, devido à sua ambigüidade em diferentes contextos. Marc Augé (1994), sociólogo francês dos 'não lugares' afirma que na segunda metade do século $X X$ ocorreu uma aceleração histórica. $O$ passado se torna história com uma velocidade impressionante. Devido ao abandono da crença num tempo orientado e na noção de progresso o tempo teria deixado de ser um princípio de inelegibilidade e nesse sentido, o produto da memória seria uma equação que congregaria os dois elementos: tempo e espaço; ou como diria Jacques Le Goff:"o homem lembra para congelar o tempo, mas sempre a partir de algum lugar”. (Le Goff, 1996: 37).

Cada tempo tem seu substrato e cada substrato temporal inclui em si singularidade e multiplicidade. O historiador Paul Ricoeur (20I3), em Tempo e Narrativa chama a atenção para o fato de que a narrativa constitui uma mediação indispensável à narrativa, seja ela histórica ou cinematográfica, por analogia. Em tom de blague, Ricoeur assevera: "O tempo não existe, mas o homem, de tempo para cá, depois que desenvergou a espinha e andou sobre as duas pernas, cismou em medi-lo, quantificá-lo" (2013). E tentou aprisioná-lo: nos calendários, anuários, agendas e, porque não nas narrativas cinematográficas. A narrativa foi a ferramenta usada para domar o tempo de vez. Desde então, a temporalidade balizou de maneira definitiva o fazer cinematográfico. Do mesmo modo, a livre experiência cinematográfica de captação das imagens em movimento, iniciada no final do século XIX, foi "enjaulada" pela narrativa linear e tornou-se um instrumento de contação de histórias.

Assim, defendemos a ideia de que os artistas que contribuíram para ampliação sobre os suportes, meios e linguagem o fizeram tanto no campo das artes plásticas quanto do cinema, pois imersa nessa concepção de que a imagem cinematográfica era capaz de uma apreensão mais temporal da produção artística, existia também a consciência de uma discussão mais ampla, que pretendia, com o dito filme de artista, negar a simples representação naturalista do cinema convencional narrativo de inspiração literária, que, para eles, engessou a produção em um sistema comercial e aprisionou a imagem nas tradicionais salas de projeção.

O artista que trabalha com a apropriação e/ou produção de imagem em movimento tem a percepção de que o tempo se constitui como uma experiência subjetiva, o tempo do narrador pode diferir do tempo do que é narrado, e esta imagem de tempo pode ser, antes, um artifício para darmos concretude à vida, mesmo podendo ser rompida a qualquer momento. $A$ ideia de que o tempo não é unidimensional, nem físico, nem natural, nem universal foi o mote conclusivo dos escritos de Paul Ricoeur. E por isso, o tempo não pode ser mais concebido como linear porque no presente (do historiador, dos cineastas, dos artistas, do espectador) essas percepções múltiplas sobre o tempo se coadunam com o 'presenteísmo' de Eric Hobsbawn; o 'presente perfeito' de Guy Debord; o 'presente opaco' de Hanna Arent; o 'presente homogêneo e vazio' de Walter Benjamim.

As mais diversas concepções de tempo podem ser aplicadas na transmutação pela qual passaram as obras que foram deslocadas para o ambiente museal, pois a abstração do tempo só se mede pela vivência. Não se "pega" o tempo, se sente.Assim, o tempo do/no cinema praticado no espaço expositivo é muito mais de um tempo rizomático, um tempo fractal, de múltiplas posi- 
ções e possibilidades de apreensão: com o perdão do truísmo, um tempo de múltiplas temporalidades.

Desde os primeiros estágios da consolidação de uma linguagem cinematográfica, diz-se que o cinema constrói temporalidades narrativas próprias. Seja com a "imagem indireta do tempo" (Deleuze, 1985) obtida na montagem de planos do cinema clássico, ou com a "imagem-tempo direta" presente em determinadas correntes do cinema moderno e contemporâneo, são incontáveis os exemplos de relações espaço-temporais estabelecidas através da experiência cinematográfica de se contar (ou não) uma estória (Vieira Jr, 2007: 5).

As diversas temporalidades do e no cinema e suas múltiplas facetas de apresentação, projeção e recepção tornaram pedra de toque para alguns artistas que assumiram papel de destaque nos discursos, narrativas e significações dos espaços expositivos e peças projetas, conjunto que nos leva a uma discussão que atravessa as fronteiras fragilmente delineadas entre a Arte Moderna e a Arte Contemporânea. A situação cinema de Katia Maciel ou o efeito cinema de Dubois ajudam a construir a compreensão do espaço da projeção num ambiente específico em que o espectador é pensado como parte ativa do processo. Por isso, como elemento narrativo de finalização, o espaço expositivo, a projeção em si e suas temporalidades constituintes tornam-se possíveis ao serem mediadas pela ação do processo de musealização, elemento intermediário entre a apreensão da experiência cinematográfica para o espaço expositivo e o espectador, sem o qual nenhuma equação ou narrativa ligada ao "dispositivo cinema” se constitui.

\section{Referências}

ARENDT, Hannah. “O Conceito de História - antigo e moderno”. In: Entre o passado e o futuro. São Paulo: Perspectiva, 2009.

AUGÉ, Marc. Os não lugares. São Paulo. Contexto. 1994.

BENJAMIN,Walter. A obra de arte na época da reprodutibilidade técnica. Disponível em: http://baixacultura.org/biblioteca/artigos-ensaios-papers/I-I-a-obra-de-arte-na-era-de-sua-reprodutibilidade-tecnical

BOURRIAUD, Nicolas. Formas de Vida: a arte moderna e a invenção de si. São Paulo: Martins Fontes, $201 \mathrm{I}$.

CANOGIA, Ligia. 198I. Quase cinema: cinema de artista no Brasil, 1970/1980. Col. Arte Brasileira Contemporânea: caderno de textos 2. Rio de Janeiro: Funarte.

COCHIARALE, Fernando e PARENTE, Andre. Filmes de artista no Brasil, 1965/I980. Rio de Janeiro: Contracapa, 2007.

D'AMARAL, Márcio Tavares. "Sobre tempo: Considerações intempestivas". In DOCTORS, Marcio (org). Tempo dos tempos. Rio de Janeiro: Jorge Zahar Editor, 2004.

DEBORD, Guy. La societé du spectacle. Paris: Gallimard, 1992.

DUBOIS, P. $O$ efeito cinema na Arte Contemporânea. In: COSTA (org.), Luiz Claudio. Rio de Janeiro: Contra Capa livraria / FAPERJ, 2009.

HOBSBAWN, Eric. Sobre História. São Paulo. Cia das Letras, 1997.

VIEIRA Jr., E.. "Algumas considerações sobre cinema e tempo nas periferias do capitalismo flexível”. In: Ciberlegenda, out/2007.

KOSELLECK, Reinhardt. Futuro Passado. Contribuição à Semântica dos Tempos Históricos. São Paulo. Contraponto, 2010. 
MACIEL, Kátia. Transcinemas. Rio de Janeiro: Contracapa, 2009.

RICOEUR, Paul. Tempo e Narrativa. São Paulo. Martins Fontes, 2013.

VIEIRA Jr., E. Algumas considerações sobre cinema e tempo nas periferias do capitalismo flexível. Ciberlegenda, out/2007.

Artigo recebido em janeiro de 2016.Aprovado em maio de 2016 